\title{
To Identify Various Parameters Leading to the Growth of Dental Care Products in Indian Market
}

\author{
Abdullah Bin Junaid ${ }^{1}$, Mohammed Imran Khan ${ }^{2}$, Mohd Usman Mansoori ${ }^{3}$, \\ Mohammad Zameer ${ }^{4}$, Syed Jahangir $\mathrm{Ali}^{5}$ \\ 1,2,3,4,5 Department of Management, Jamia Hamdard, New Delhi, India
}

\begin{abstract}
The study focuses on the survey on dental care products through various specialized doctors who were practicing in reputed hospitals of Delhi. Doctors surveyed under the study were BDS and MD as well. This survey was carried out to find out the various factors which are associated with dental therapy and to find out various hurdles that come into its acceptance. The Global Industry Analyze the global market for Dental Supplies to reach upto US\$19.4 billion by the year 2017. This study has been done through face to face conversation with eighty dentists specialized in their field and who were prescribing dental products, in different hospitals of Delhi. These interviews were beneficial in comparatively analyzing the pros and cons of dental therapy and its methods of drug administration. A randomized controlled trial was done to evaluate the impact of dental therapy. The data collected by the survey of 80 dentists was analyzed by different tests of SPSS (Statistical Software for Social Science) version 16. Results of the study indicate that the major practicing group comprises of independent dentist working in private clinic, so individual sales effort should also target these dentist apart from institutional selling. The two classes of drugs namely antibiotics and Non-steroidal antiinflammatory drugs are the most important group to be target as they are used most frequently by the dentists.
\end{abstract}

Key Words: Dental Industry, Dental Products, Indian Dental Market, Oral Healthcare

\section{Introduction}

According to Global Industry Analysis the global market for Dental Supplies is projected to reach US $\$ 19.4$ billion by the year 2017, driven by an aging population, increasing awareness about oral care, rise in demand for preventive and cosmetic dental procedures, and technological developments. Rising per capita spending across developed countries and increasing disposable incomes in developing countries are driving global growth. The dental equipment market consists of devices used in diagnosing dental diseases/conditions and treating the same. These include dental chairs, hand pieces, CAD/CAM systems, scaling units, instrument delivery systems, dental lasers, intra oral and extra oral radiology equipment, and CBCT scanners. Emerging technologies will have a great impact over the growth of the market, as these will help reduce the overall turnaround time for dental procedures and also improve the efficiency of practitioners. Global Dental Equipment Market will raise upto worth $\$ 6.1$ Billion by 2016. (MarketsandMarkets, 2012)

Due to the vast potential size of Indian dental market India is among one of the largest country for marketing the dental products. India is capable of creating tremendous demand for better health due to the huge size of Indian population and a sustained economic growth. Taking into consideration over 1,25,000 dental practitioners, 20,000 fresh graduates annually entering the workforce which is expected to swell to 225000 shortly, and with 290 dental colleges in India which is the largest number in the world, the market for dental equipment and material is estimated to be around US\$ 38 million annually, an increase of $25-30 \%$ (Indian Dental Association). The Indian health care market is considered to be among the world's top ten markets.

In India, Oral healthcare is an important aspect of the overall health of an individual. Indian dental care services market, constituted by dentists and dental ancillary services, was estimated to be US $\$ 739$ million in 2010 and is expected to reach US $\$ 1302.5$ by 2015 at a CAGR of 12 percent. With increased awareness, and rise in disposable incomes, the dental care market in India is gaining importance at a much faster rate. Frost \& Sullivan observes a shift, where one does not just visit the dentist, when one has serious dental problems. It has also been observed that there is an increasing demand for cosmetic dentistry like whitening, tooth reshaping, chipped teeth, etc. by this we can say that the awareness level of individuals is increasing and they are becoming more conscious about their look.

\section{The size of the Market}

The Indian Healthcare market is at about US\$ 60 billion. The industry is expected to grow to US\$79 billion in 2012. The Indian healthcare market is one of the largest services sectors contributing $2 \%$ to the country's GDP. It has grown by more than 50\% since 2005 and is expected to quadruple to $\$ 150$ bn by 2017 
(ida.org.in). The private healthcare providers also account for the largest share of India's health expenditure. The public spending on urban and rural healthcare is $23 \%$ and $30 \%$ respectively. Private agencies account of nearly $75 \%$ of urban and $66 \%$ of rural healthcare funding (ida.org.in). The large domestic market complemented by the inflow of medical tourists that has increased almost 20-fold from 10,000 in 2000 to about $1,80,000-2,00,000$ in 2006. There are four types of Indian healthcare facilities: private clinics, government hospitals, teaching institutions and laboratories. Private sector corporate entities like the Apollo Hospitals, Wockhardt Hospitals and Fortis Healthcare, Max Healthcare have aggressive expansion plans. The government has invested large sums in healthcare as part of an on-going effort to provide better healthcare facilities. India is among the top five countries that offer health services to poor in public sector. Substantial amounts of varying subsidies for provision of healthcare to the economically poor are being provided by the government. Additionally, to set up new dental practice in the service sector, the subsidies range between $15 \%$ and $25 \%$ subject to a limit of US \$20,000. Financial assistance from nationalised banks is provided at $9 \%$ to $10 \%$ interest for such new dental practices. The subsidies are primarily made as the poor could not afford healthcare services. The share in total private consumption expected to increase by $10 \%$ (ida.org.in).

\section{The Dental Industry at Present}

The total market for the Dental equipment and materials in India is estimated to be around US\$ 50 million annually (ida.org.in.) The potential size of India's dental market is vast and it is expected that India will shortly become one of the largest single country markets for overseas dental device and materials exporters which is increasing by $25-30 \%$ annually (ida.org.in). About $90 \%$ of India's annual requirement of dental equipment, instruments and materials demand is met mainly by imports primarily from Germany, USA, Italy, Japan and recently from China, as India has less number of manufacturers and is largely dependent on imports. As regards the possibility of importing dental equipment and materials to India, the leading categories constitute consumable items, implants, X-Rays, dental units and imaging systems. Another area that is experiencing steady growth is that of instruments of all types, with a major increase in dental laboratory equipment and materials, dental drills, scalers and hand pieces. The growing awareness about cross-infections and government controls has brought dental professionals to invest more in sterilization equipment/devices. India's market for dental products is extremely dynamic, with a current estimated growth rate of between 25 to $30 \%$ (ida.org.in).

\section{Literature Review}

There is an urgent need for analyzing the dental workforce of the country so as to study the scope of dentistry in the coming years, since we are stepping into the next decade (Ahuja and Parmar, 2011). To strengthen and build partnership the dental educators including those working in dental schools must work together within these communities. This can only happen by working together for a common goal that is to meet the challenges of the diversity of oral health care need in our nation and to maintain the strong dental education system (Ahuja and Parmar, 2011). Oral hygiene instructions including correct tooth brushing techniques as well as scaling and root planning with regular dental follow-up could play a significant role in prevention of biofilm accumulation (Grover and Aggarwal, 2011).

The major reason for tooth loss in adult is Periodontitis. There is a very urgent need for standardized population-based studies with a robust design to identify the true prevalence of periodontitis, which in turn will help in planning oral health policies and creating the necessary infrastructure (Shajuet al, 2010) the issues like oral health promotion, promotion of research in oral health, development of health information system should be addressed by the National Program on Oral Health. The State Government before issuing the essentiality certificate must take undertaking from the Institutions that in-view of the acute shortage of Dental manpower in their area, it will be able to improve the oral health status of the population of the adopted PHC's by effectively utilizing the dental manpower during field posting of the students and the Interns and submit report of the work undertaken twice a year to the State Government Office (Government of India and WHO Report, 2007).

As an expression of attitudes, community groups, particularly the underprivileged, have clear feelings about the priorities in the health care field and the way health care is rendered. They realize their lack of expertise in the technical and scientific aspects of health care, but they want a real control in matters of priority, delivery of care, and perhaps even personnel selection. In any such programs, priority should be given to lower class people having higher prevalence of diseases and unmet treatment needs (Chandrasekhar and Reddy, 2011). Pharmacists have long served as the medication experts of the health care team and, due to their knowledge and accessibility, are frequently approached by the general public and other professionals to answer health-related questions (Kumar et al, 2008). According to Maunder and Landes a primary care team meetings and regular multidisciplinary should be set up. A list of key contacts within the area of practice to be provided to pharmacists for advice regarding tobacco cessation, clarifications regarding oral health and Support for window displays, especially about targeting health issues, including oral health (Maunder and Landes,2005). 
In order to bring oral health care to the doorsteps of the people, services for oral health care at the primary level can be established. This will need to be supported by referral mechanisms for those who need specialized treatment in secondary or tertiary centers (Patroet al, 2008). The untreated oral cavity has its deleterious effects on comfort, aesthetics, speech, mastication and, consequently, on quality of life in old age (Talwar and Chawla, 2008). Coordination of services for the elderly through a multidisciplinary team, including colleagues from geriatric medicine, is important and would contribute to meeting the dental care workload efficiently (Talwar and Chawla, 2008). A research must be done before the potential for oral infections to cause damage in other sites of the body can definitely be established (Nayak and Nayak, 2007). Although several methods such as topical or systemic use of fluorides, fissure sealants, and dietary control have been developed to prevent dental caries, the efficacy of these methods is not enough to eradicate dental caries in humans; however, there are a few studies on the efficacy of caries vaccines in humans (Shivakumar et al, 2009). The dental insurance sector in India is at a nascent stage as only a handful of dental insurance plans are available. Another important area where business potential lies in is the Dental Tourism. According to Frost \& Sullivan, Dental Tourism forms 10 percent of the total medical tourism industry in India; this is projected to grow at 30 percent per annum, into an INR 9,500 Crore (US \$179.500) industry by 2015 .

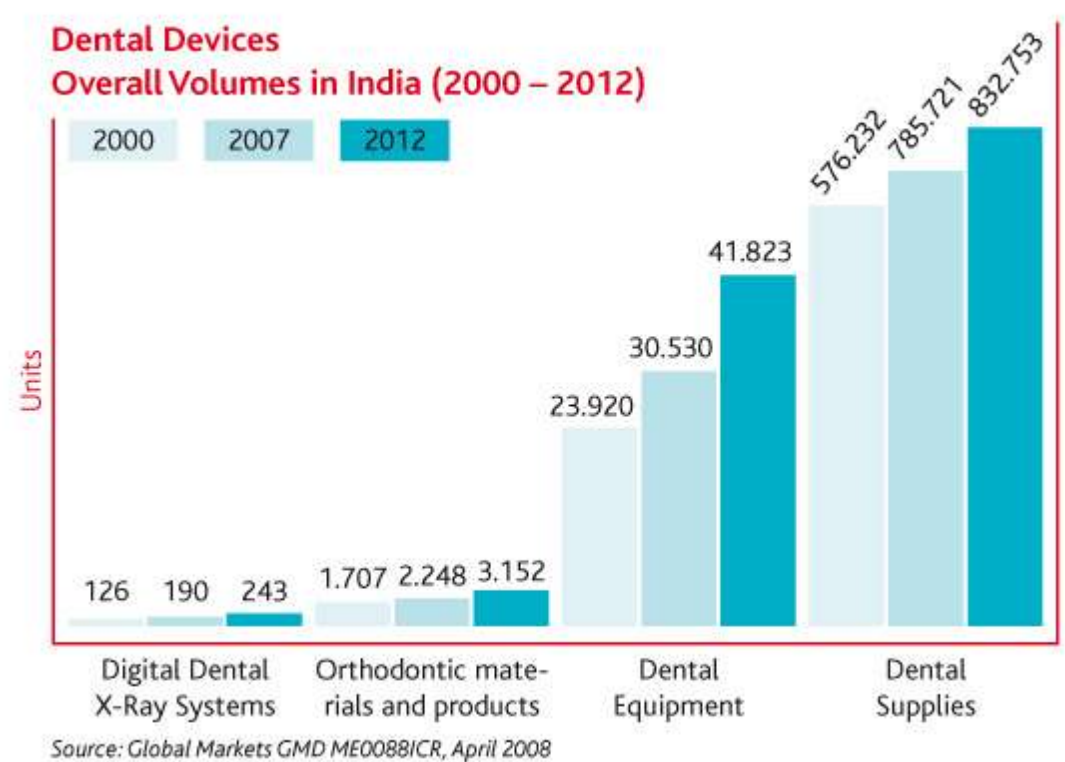

Figure: 1

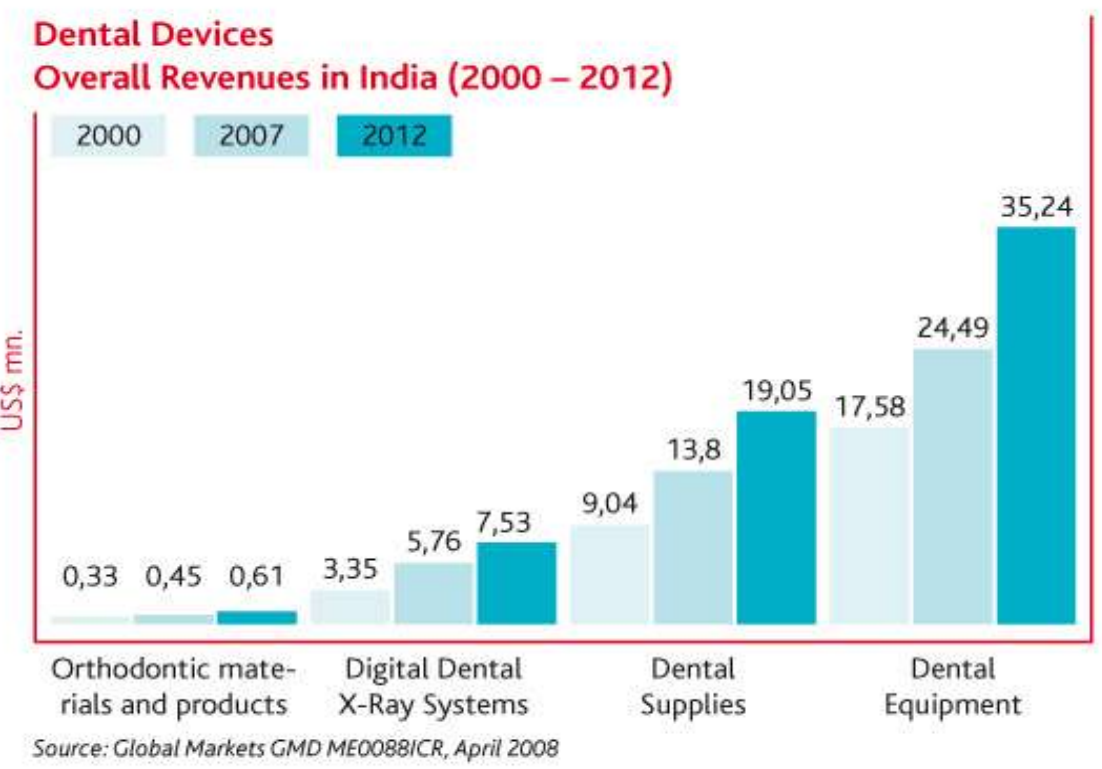

Figure: 2 
3.1 Area of study

\section{Research Methodology}

Delhi.

\subsection{Sample size}

A survey of total 80 dentists was done.

\subsection{Sampling techniques}

Random Sampling Technique.

\subsection{Data collection}

A survey was carried for primary data collection usingstructured questionnaire and the direct interview with the dentist.The data was collected from the 80 dentist.

Through observation, interview and structured questionnaire data was collected on various aspects of dental segments of drug like highest ranking brand, awareness about the company etc.

\subsection{Analysis}

SPSS (Statistical Package for the Social Sciences) software was used for data analysis.

\section{Data Analysis}

\begin{tabular}{|l|r|r|r|r|}
\hline & Q1 & & \\
& Frequency & Percent & Valid Percent & $\begin{array}{c}\text { Cumulative } \\
\text { Percent }\end{array}$ \\
\hline Valid private clinics & 65 & 81.2 & 81.2 & 81.2 \\
hospitals & 11 & 13.8 & 13.8 & 95.0 \\
nursing home & 1 & 1.2 & 1.2 & 96.2 \\
private hospitals & 3 & 3.8 & 3.8 & 100.0 \\
Total & 80 & 100.0 & 100.0 & \\
\hline
\end{tabular}

Table: 1

Within the dental survey 81.2 percent of the doctors were covered from private clinics, 13.8 percent from government hospitals, 3.8 percent from private hospitals and 1.2 percent form nursing homes.

Q2

\begin{tabular}{|l|r|r|r|c|}
\hline & Frequency & Percent & Valid Percent & Cumulative \\
\hline Valid bercent \\
\hline
\end{tabular}

Table: 2

As per the qualification of doctors from the table 2 we can say that 78.3 percent doctors are BDS, 20 percent are MDS and only 6.2 percent are FIG.

\section{Q3}

\begin{tabular}{|r|r|r|r|r|}
\hline & $\begin{array}{c}\text { Frequenc } \\
\mathrm{y}\end{array}$ & Percent & $\begin{array}{c}\text { Valid } \\
\text { Percent }\end{array}$ & $\begin{array}{c}\text { Cumulative } \\
\text { Percent }\end{array}$ \\
\hline Valid $0-10$ & 43 & 53.8 & 53.8 & 53.8 \\
$10-20$ & 34 & 42.5 & 42.5 & 96.2 \\
$20-30$ & 3 & 3.8 & 3.8 & 100.0 \\
Total & 80 & 100.0 & 100.0 & \\
\hline
\end{tabular}

Table: 3 
Table 3 shows the experience of the doctors. 53.8 percent doctors covered have an experience of 0 to 10 years, 42.5 percent doctors covered are having an experience of 10 to 20 years and around 3.8 percent doctors that are covered in the survey were having an experience of around 20 to 30 years.

\begin{tabular}{|c|c|c|c|c|c|}
\hline \multicolumn{6}{|c|}{ Q4 } \\
\hline & & Frequency & Percent & $\begin{array}{l}\text { Valid } \\
\text { Percent }\end{array}$ & $\begin{array}{c}\text { Cumulative } \\
\text { Percent }\end{array}$ \\
\hline \multirow[t]{4}{*}{ Valid } & $0-10$ & 42 & 52.5 & 52.5 & 52.5 \\
\hline & $10-20$ & 32 & 40.0 & 40.0 & 92.5 \\
\hline & $20-30$ & 6 & 7.5 & 7.5 & 100.0 \\
\hline & Total & 80 & 100.0 & 100.0 & \\
\hline
\end{tabular}

Table 4 shows the number of patients that each of the doctor diagnose in each of its OPD. From the above table we can conclude that most of the doctors diagnose in between 0 to 20 patients in each of their OPD.

Q5

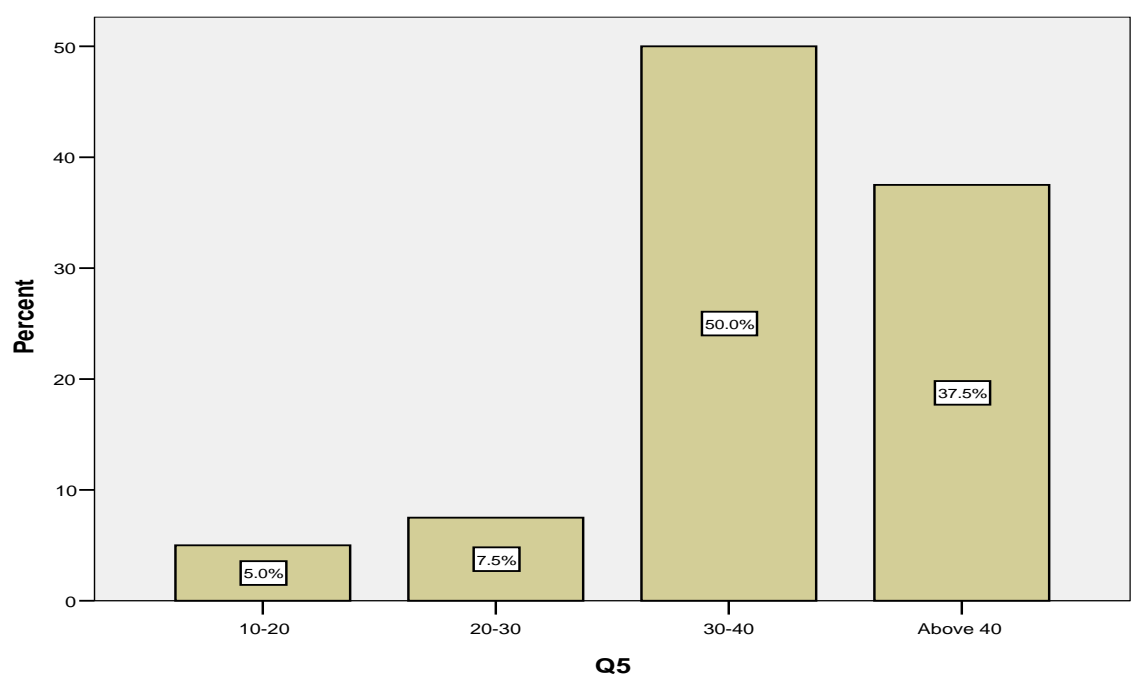

Figure: 3

Figure 3 shows that 50 percent of the doctors said that patients under the age group of 30 years to 40 years age are mostly suffering from dental problems. However, the next major age group is above 40 years.

\section{Q7}

\begin{tabular}{|c|c|c|c|c|c|}
\hline & & Frequency & Percent & Valid Percent & $\begin{array}{c}\text { Cumulative } \\
\text { Percent }\end{array}$ \\
\hline \multirow[t]{4}{*}{ Valid } & acute & 5 & 6.2 & 6.2 & 6.2 \\
\hline & chronic & 51 & 63.8 & 63.8 & 70.0 \\
\hline & both & 24 & 30.0 & 30.0 & 100.0 \\
\hline & Total & 80 & 100.0 & 100.0 & \\
\hline
\end{tabular}

By analyzing table 5 we can say that most of the patients who are suffering from any of the dental disorder comes to doctor for diagnosis in chronic condition. 


\begin{tabular}{|c|c|c|c|c|c|}
\hline \multicolumn{6}{|c|}{ Q9 } \\
\hline & & Frequency & Percent & Valid Percent & $\begin{array}{c}\text { Cumulative } \\
\text { Percent }\end{array}$ \\
\hline \multirow[t]{10}{*}{ Valid } & dolosaidMR & 11 & 13.8 & 13.8 & 13.8 \\
\hline & SN-15 & 18 & 22.5 & 22.5 & 36.2 \\
\hline & hoiraK & 2 & 2.5 & 2.5 & 38.8 \\
\hline & hexidine & 11 & 13.8 & 13.8 & 52.5 \\
\hline & chloehex & 10 & 12.5 & 12.5 & 65.0 \\
\hline & dologel & 2 & 2.5 & 2.5 & 67.5 \\
\hline & thermoseal RA & 17 & 21.2 & 21.2 & 88.8 \\
\hline & sensodent-K & 3 & 3.8 & 3.8 & 92.5 \\
\hline & 15 & 6 & 7.5 & 7.5 & 100.0 \\
\hline & Total & 80 & 100.0 & 100.0 & \\
\hline
\end{tabular}

Table: 6

During the study we found that most of the patients were suffering either from teeth pain or from sensitivity and table 6 shows that most of the doctors prefer SN-15 for tooth pain and thermoseal RA is the most preferred brand for teeth sensitivity.

\begin{tabular}{|c|c|c|c|c|c|}
\hline \multicolumn{6}{|c|}{ Q10 } \\
\hline & & Frequency & Percent & Valid Percent & $\begin{array}{c}\text { Cumulative } \\
\text { Percent }\end{array}$ \\
\hline \multirow[t]{4}{*}{ Valid } & otc & 2 & 2.5 & 2.5 & 2.5 \\
\hline & prescription & 54 & 67.5 & 67.5 & 70.0 \\
\hline & surgery & 24 & 30.0 & 30.0 & 100.0 \\
\hline & Total & 80 & 100.0 & 100.0 & \\
\hline
\end{tabular}

Table: 7

According to table 7 we can say that about 67.5 percent of the doctors prescribe prescription drugs for the treatment of teeth problems and 30 percent of the doctors go for surgery.

Q11

\begin{tabular}{|rl|r|r|r|r|}
\hline & & Frequency & Percent & Valid Percent & \multicolumn{2}{|c|}{$\begin{array}{c}\text { Pumulative } \\
\text { Vercent }\end{array}$} \\
\hline Valid & $51-75 \%$ & 19 & 23.8 & 23.8 & 23.8 \\
& $76-100 \%$ & 61 & 76.2 & 76.2 & 100.0 \\
& Total & 80 & 100.0 & 100.0 & \\
\hline
\end{tabular}

Table: 8

When asked about the improvement in the symptoms after the treatment table 8 shows that about 76.2 percent of the doctors feel that patients were relived from the symptoms in between 76 percent to 100 percent. 


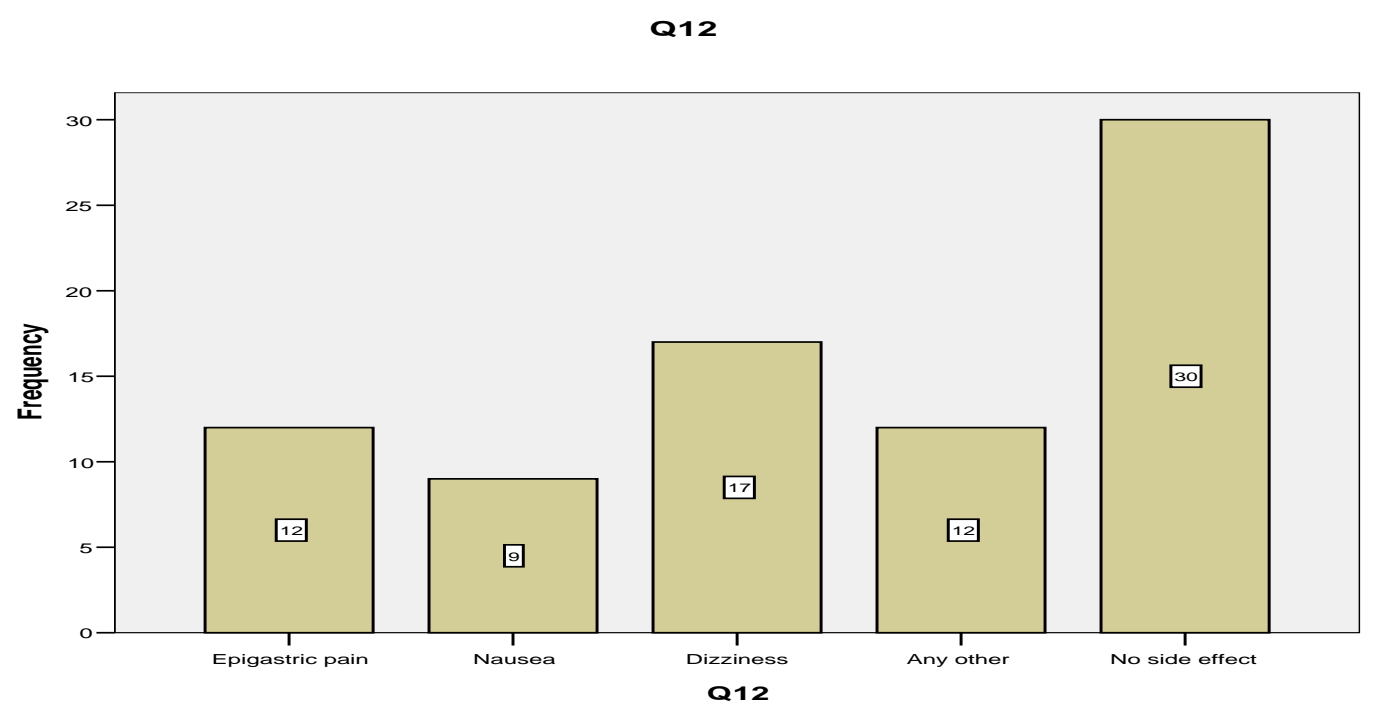

Figure: 4

Figure 4 shows that 37.5 percent doctors feel that there are no side effects of the drugs the prescribe for the treatment of dental disorders but about 21.2 percent doctors have said that dizziness is the major side effect while using the drugs of dental disorders.

\begin{tabular}{|ll|r|r|r|r|}
\hline & & & Q14 & \multicolumn{2}{c|}{$\begin{array}{c}\text { Cumulative } \\
\text { Percent }\end{array}$} \\
\hline Valid & $0-200$ & Frequency & Percent & Valid Percent & 1.2 \\
& $200-400$ & 41 & 1.2 & 1.2 & 52.5 \\
& $400-600$ & 24 & 30.0 & 51.2 & 82.0 \\
above 600 & 14 & 17.5 & 17.5 & 100.0 \\
Total & 80 & 100.0 & 100.0 & \\
\hline
\end{tabular}

From table 9 we can say that 51.2 percent of the doctors have a opinion that the average cost of treatment for dental disorders should be in between rupees 200 to rupees 400 per week. They said that this cost can be easily affordable by the patients.

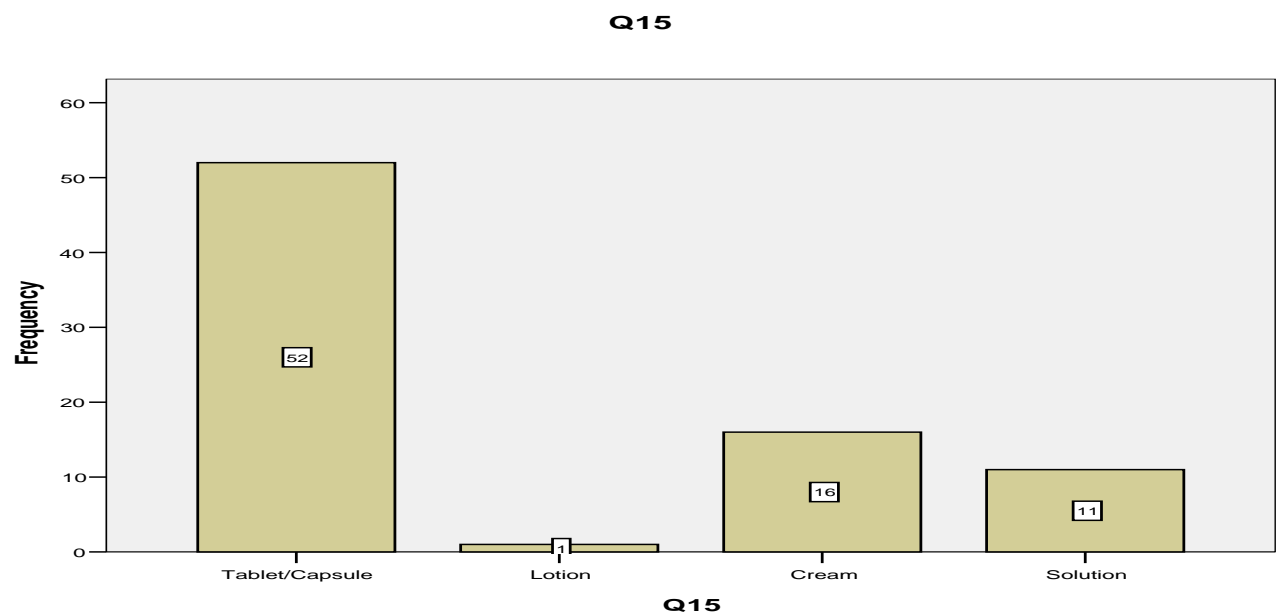

Figure: 5 
Figure 5 shows that 65 percent of the doctors feel that tablet and capsules are the easiest dosage form for dental therapy and the feel that these two forms are easily accepted by the patients.

\section{Q16}

\begin{tabular}{|ll|r|r|r|r|}
\hline & & & & \multicolumn{2}{c|}{$\begin{array}{c}\text { Cumulative } \\
\text { Percent }\end{array}$} \\
\hline Valid & container & 10 & 12.5 & 12.5 & 12.5 \\
& tubes & 16 & 20.0 & 20.0 & 32.5 \\
& strip & 54 & 67.5 & 67.5 & 100.0 \\
& Total & 80 & 100.0 & 100.0 & \\
\hline
\end{tabular}

Table: 10

As shown in the above table 10 that the most accepted dosage form are the tablets and capsules hence table 13 also noted that the most effective packaging type is the strip packaging. This strip packaging is also preferred by the doctors and around 67.5 percent of the doctors have agreed on this particular type of packaging.

Q17

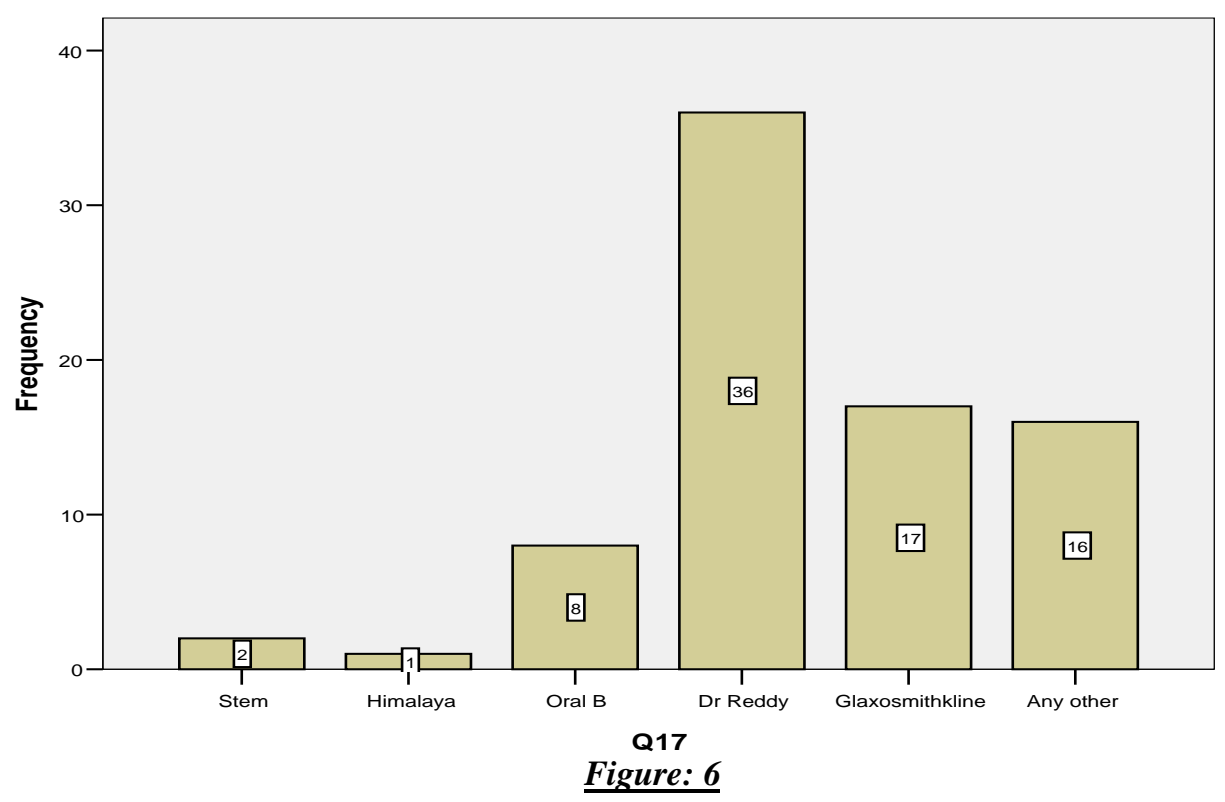

When asked to rank the company as per the best product figure 6 shows that 45 percent of the doctors have the opinion that Dr. Reddy is the best company for the dental products.

\section{FINDINS}

Results of the study indicate that the major practicing group comprises of independent dentist working in private clinic, so individual sales effort should also target these dentist apart from institutional selling. The two classes of drugs namely antibiotics and Non-steroidal anti-inflammatory drugs are the most important group to be target as they are used most frequently by the dentists. The newer therapy and drugs need to be communicated to the dentists because fewer dentists were having a specialization. The dentists who have less than 10 years of experience should be communicated about the brands and company in order to establish a long lasting brand loyalty. All the dentist should be covered for brand promotion as the number of patients treated per doctor is low. The patient of 30-40 years age group of both genders should be specifically targeted for dental education as they are most prone for developing the dental diseases. So that they should see the dentist in acute stage of dental problem before it turns chronic. The reasons for common dental disease should be communicated to the patient through advertisement and patient education so that disease can be prevented from turning into chronic. This will help in achieving better compliance in treating the disease.

The role of OTC drugs like mouthwash should be recognized in preventing the dental disease and better dental hygine.OTC drugs will also help in prevention of complications of periodontal diseases for which improvement in disease condition was low as compared with RCT (root canal treatment) and crown bridging. 
There was no major side effect and development of tolerance by the treatment regimen due to short duration of therapy in dental disease. The major cost associated with dental treatment was fee of the dentist on surgical procedures. Generic drugs should be promoted to lower the overall cost of treatment for patient. Conventional dosage form of drugs like tablet and capsule is having the best compliance with requirement of dentist.

\section{Recommendations} are as follows:

Certain recommendations are suggested based on the observations and analysis of the study and these 1) It was told by the dentist during the study that frequency of visits by medical representatives to the dentist was not satisfactory. So a separate promotion plan for the brands should be designed for dental practitioners that match with the strategy of the company. This plan should have a special emphasis on the categories of drug like antibiotics and anti-inflammatory as these are most frequently used by the dentists.

2) It was found that patient education for dental hygiene should be done in order to assure better dental health. So, advertisement and dental awareness camp should be undertaken to educate patient regarding the common dental disease and their prevention. The age group 30-40 years should be specially targeted for this as they are most vulnerable for dental disease.

3) Promotion of generic drugs should be done to reduce the overall cost of treatment by the dentist in order to make dental care more affordable.

4) Independent dentist in private clinic should be targeted along with institutional dentist in order to establish brand and brand loyalty.

5) Patient should be encouraged to visit dentist in acute stage of disease rather than waiting the disease to turn into chronic.

\section{References:}

[1] http://www.ida.org.in/Mainconfig.aspx?ModuleId=105\&id=7\&categoryid=3383\&IsExpandable=true, accessed on 20 ${ }^{\text {th }}$ March 2012, 9:00 PM.

[2] Ahuja, N K et al , 2011, Demographics \& Current Scenario With Respect To Dentists, Dental Institutions \& Dental Practices In India $<$ http://www.ijds.in/function.php?fuse $=23 \&$ SrNo=10\&CurrentIssue=No\&IssueVol=Vol.\%203\&IssueNumber=Issue $\% 202 \&$ ArticleID $=125$, accessed on $9^{\text {th }}$ April 2012 at 12:30 PM.

[3] Shaju, J 2010, Prevalence of periodontitis in the Indian population: A literature reviewaccessed on $10^{\text {th }}$ April 2012 at 2:30 PM<,http://www.ncbi.nlm.nih. gov/pmc /articles/PMC3 134042/\#sec1 -4>

[4] GOI-WHO Collaborative Programme, 2007, Formulation of Guidelines for Meaningful and Effective Utilization of Available Manpower at Dental Colleges of Primary Prevention of Oro-dental Problems in the Country, accessed on $4^{\text {th }}$ April 2012 at $11: 30$ PM.<http://www. whoindia.org/LinkFiles/Oral_Health_Oro-Dental_Problem_WHO_Project_Guidelines.pdf>

[5] Patro, B K, Ravi Kumar B, Goswami A, Mathur VP, Nongkynrih B,2008,Prevalence of dental caries among adults and elderly in an urban resettlement colony of New Delhi, accessed on $5^{\text {th }}$ march 2012 at 1:30 PM<http://www.ijdr.in/article.asp?issn=09709290; year=2008; volume $=19 ;$ issue $=2$; spage $=95$; epage $=98$; aulast $=$ Patro $>$

[6] Talwar M, Chawla HS, 2008, Geriatric dentistry: Is rethinking still required to begin undergraduate education?, accessed on $28^{\text {th }}$ march,2012,10 AM,http://www.ijdr.in/article .asp?issn=09709290; year=2008; volume $=19 ;$ issue $=2$; spage $=175$; epage $=177$; aulast $=$ Talwar

[7] KM Shivakumar, SK Vidya, GN Chandu 2009, Dental caries vaccine ,accessed on 22 march, <http://www.ijdr.in/article.asp?issn=0970-9290;year=2009; volume=20;issue=1;spage=99; epage=1 06; aulast=Shivakumar >

[8] Baig M R, Rajan M, 2007, Effects of smoking on the outcome of implant treatment: A literature review, accessed on $27^{\text {th }}$ February,<http://www.ijdr.in/article.asp?issn=0970-9290;year=2007; volu me=18;issue=4; ;page=190; epage=195; aulast=Baig >

[9] Ida.org.in, 2010, Future of Dentistry lies in India, accessed on 03 ${ }^{\text {rd }}$ March 2011, < http://annualconference.ida.org.in/mainconfig1 aspx ?Categoryid=5544\&id=16\&Moduleid=105\&contentId=26\&Isxpandable=true $>$

[10] Freedoniagroup.com, 2008, Dental Products \& Materials to 2012 - Demand and Sales Forecasts, Market Share, Market Size, Market Leaders, accessed on 01 March 2011, <http://www.freedoniagroup.com/Dental-Products-And-Materials.html>

[11] Dentalmarketresearch.com, 2010, What is holding the dental market back?, accessed on 26 February 2011, <http://www.dentalmarketresearch.com/index.php/2010/07/consumer-choice/>

[12] Jose, S 2010, Global Dental Supplies Market to Cross \$16 Billion by 2015, According to New Report by Global Industry Analysts,Inc.,accessedon25February2011, <http://www.prweb.com/releases/dental_supplies/dental_implants/prweb4596444.htm> 